\title{
Remodelling of Lipid Rafts during In vitro Capacitation and Acrosome Reaction of Ram Spermatozoa
}

\author{
Carmen Colas ${ }^{1}$, Rosaura Perez-Pe ${ }^{2}$, Adriana Casao ${ }^{2}$, Mario Ollero ${ }^{3}$, Lucia Calleja², Margarita Gallego ${ }^{4}$, Teresa Muiño- \\ Blanco $^{2 *}$ and Jose A Cebrian-Perez ${ }^{2}$
}

${ }^{1}$ Fundación Centro Nacional de Investigaciones Cardiovasculares Carlos III, Departament of de Cardiología Regenerativa.C/ Melchor Fernández Almagro 3, E-28029 Madrid, Spain

${ }^{2}$ Department of Biochemistry and Molecular and Cell Biology, School of Veterinary Medicine, University of Zaragoza, Spain

${ }^{3}$ Université Paris Est-Créteil, INSERM U955, Créteil, France

${ }^{4}$ Animal Pathology, School of Veterinary Medicine, University of Zaragoza, Spain

\begin{abstract}
Background: Lipid rafts are often known as Detergent-Resistant Microdomains (DRMs). We report for the first time the presence of two lipid raft markers, caveolin-1 and ganglioside GM1, on the ram sperm surface, and the effect of in vitro capacitation and acrosome reaction on these marker distributions, the protein content and lipid composition of DRM and non-DRM fractions.
\end{abstract}

Methods: Caveolin-1 and ganglioside GM1 were evidenced by immunocytochemical and fluorescence analysis, respectively. DRM and non-DRM fractions were separated by an OptiPrep ${ }^{\mathrm{TM}}$ density gradient. Cholesterol by fluorometry, GM1 by peroxidase reaction, protein content by spectrophotometry, and fatty acid profiling by gas chromatography were determined.

Results: Caveolin-1 was evidenced at the acrosome of $59.2 \pm 4.3 \%$ fresh spermatozoa, and the proportion of stained cells increased $(P<0.05)$ after capacitation. GM1 was detected at the post-acrosome and tail of all spermatozoa, and no change was found after capacitation. Cholesterol and GM1 were distributed all along the gradient, with a peak in DRM fractions. A higher proportion $(P<0.001)$ of saturated fatty acids was found in DRM fractions, confirmed by the unsaturation index and a higher lipid/protein ratio. In vitro capacitation induced a decrease in the content of saturated fatty acids in both DRM $(P<0.001)$ and non-DRM $(P<0.01)$ fractions. Polyunsaturated fatty acids increased in DRMs after the acrosome reaction. All treatments resulted in lower content of cholesterol and proteins in $D R M(P<0.01)$ and non-DRM fractions $(P<0.001)$, and a higherGM1 content in DRMs $(P<0.05)$.

Conclusions: Lipid raft-like microdomains were isolated in a discrete region of the gradient. Their high content of saturated fatty acids confers a highly ordered environment. Their composition is modified during in vitro capacitation and acrosome reaction.

General significance: These results represent the first characterization of ram sperm DRM, and may contribute to a better understanding of the sperm fertilizing potential acquisition mechanism.

Keywords: DRMs; Cholesterol; Fatty acids

\section{Introduction}

Spermatozoa are cells with a limited biosynthetic capability $[1,2]$. Hence, their functionality is mainly controlled by external factors acting through cell surface and plasma membrane components. Proteins from the epididymal and seminal plasma are adsorbed onto the sperm surface as they pass through the male and the female reproductive tracts. The final result of this remodelling is a functional mature sperm with an adequate plasma membrane for specific interactions with the egg during fertilization.

Moreover, sperm are highly polarized cells with two functional parts, and their membranes can be categorized into different compartments. In the sperm head, the plasma membrane surrounds the acrosome, the equatorial segment and the post-acrosomal region. These sperm surface areas are known to be involved in zona pellucida binding, acrosome reaction, and membrane fusion during fertilization. Several experimental approaches have shown that the sperm surface is regionalized in these areas $[3,4]$ in spite of the absence of a bilayer spanning structure to prevent mixing of diffusible membrane proteins or lipids [5].

The fluid mosaic model [6] used since the 1970s to understand the cell plasma membrane structure and functions, has gained in complexity with the increasing knowledge of compartmentalized domains of biological membranes. For spermatozoa in particular, the Singer-Nicholson model does not adequately explain the restricted lateral diffusion of their membrane surface molecules. Instead, a relatively new concept known as lipid rafts is increasingly being investigated in sperm cells as well as in mammalian cells to gain a better understanding of these phenomena.

Membrane rafts are defined as small, heterogeneous, highly dynamic domains that serve to compartmentalize cellular processes [7]. These membrane microdomains are associated with a heterogeneous group of proteins which float in the bulk sphingolipid-cholesterol phase of

${ }^{*}$ Corresponding author: T Muiño-Blanco, Departamento de Bioquímica y Biología Molecular y Celular, Facultad de Veterinaria, C/ Miguel Servet, 177. 50013- Zaragoza, Spain, Tel: 34976 761639; E-mail: muino@unizar.es

Received March 28, 2012; Accepted May 08, 2012; Published May 12, 2012

Citation: Colas C, Perez-Pe R, Casao A, Ollero M, Calleja L, et al. (2012) Remodelling of Lipid Rafts during In vitro Capacitation and Acrosome Reaction of Ram Spermatozoa. Biochem Anal Biochem S5-001. doi:10.4172/2161-1009. S5-001

Copyright: ( 2012 Colas C, et al. This is an open-access article distributed under the terms of the Creative Commons Attribution License, which permits unrestricted use, distribution, and reproduction in any medium, provided the original author and source are credited. 
the membranes. The unique, ordered properties of these domains are due to hydrophobic interactions between their saturated fatty acids and the rigid structure of intercalated cholesterol. These properties result in the resistance of lipid rafts to solubilisation by a number of nonionic detergents, commonly Triton X-100. These microdomains float in a discontinuous density gradient, due to their low density. This is the reason why lipid rafts are generally identified with DRMs (detergentresistant membranes). Because the definition of raft is based on the methodological method for their isolation, and to avoid confusion, we should make the distinction between membranes that can be isolated from detergent lysates (DRMs), and domains that may exist in cells (lipid rafts) [8].

Mammalian sperm cells have a highly differentiated morphology, which is reflected in their membrane surface properties [9]. When mammalian spermatozoa are ejaculated, they are unable to fertilize the Oocyte. They acquire fertilizing potential by the process known as capacitation that takes place during the sperm transport throughout the female genital tract. During capacitation, the sperm membrane protein and lipid organization changes dramatically [10-12]. These changes result in the capacitated state, which allows sperm to bind to the zona pellucida and the acrosome to react.

The plasma membrane of ram spermatozoa displays some particularities. The cholesterol: phospholipid ratio (0.38) is considerably lower than that in other mammalian species [13], which could be the reason why albumin-mediated cholesterol efflux might not be necessary during ram sperm capacitation $[14,15]$. This special low content in cholesterol might also be related to the increased time required for ram sperm capacitation [16], and the high sensitivity to cryodamage $[17,18]$. Likewise, the phospholipid-bound fatty acid composition and, particularly, the very high polyunsaturated:saturated fatty acid ratio in the ram sperm membrane may also influence membrane susceptibility $[19,20]$.

Several sterols, sphingolipids, glycolipids and glycosylphosphatidylinositol- (GPI-) anchored proteins have been reported in lipid rafts of different types of cells, including spermatozoa [21-23]. GM1 ganglioside and proteins such as caveolin [24,25]or flotillins are commonly used as lipid raft markers. However, although these microdomains generally possess a distinctive composition, not all rafts are identical in terms of either the lipids or the proteins that they contain [21].

Lipid rafts are highly dynamic and lateral movements have been described in various cell types in response to physiological stimuli. A multiplicity of cellular functions has been associated with these lipid microdomains, such as membrane trafficking, cellular signal transduction or viral entry [26]. In gametes, lipid rafts have been related to sperm maturation, fertilization, and early embryogenesis [27]. Furthermore, certain proteins involved in gamete membrane fusion and zona binding are enhanced in DRMs[28], which suggests that lipid rafts could be involved in sperm- zona pellucida binding and the acrosome reaction [29]. Following in vitro capacitation, membrane rafts become highly enriched in zona binding proteins [2830]. However, contradictory results have been reported, and although some authors have described a redistribution of DRMs after in vitro capacitation [29-31], others [32] found no change in the distribution of raft markers after the induction of this process.

Despite the numerous studies on lipid rafts, there is to our knowledge no published account of the composition of these microdomains in ram spermatozoa. In this study, we describe for the first time the localization of two lipid raft markers, caveolin-1 and GM1, on the ram sperm surface, and the influence of in vitro capacitation and the acrosome reaction on their distribution. Moreover, we analyze the protein content and lipid composition of DRM and non-DRM fractions isolated from ram spermatozoa in three physiological states, namely fresh, capacitated and acrosome-reacted.

\section{Materials and Methods}

\section{Sperm preparation}

All the experiments were performed with fresh semen taken from nine mature Rasa aragonesa rams using an artificial vagina. All the rams belonged to the National Association of Rasa aragonesa Sheep Breeders (ANGRA) and were 2-4 years old. They were housed under uniform nutritional conditions at the Experimental farm of the University of Zaragoza in compliance with the requirements of the European Union Directive for Scientific Procedures. All experimental procedures were performed under the supervision of the Ethics Committee of the University of Zaragoza. The sires were kept apart, and semen was collected every two days, in two successive matings each day. Under these conditions, and using second ejaculates, individual differences are very low, as we have already reported [33]. We used pooled ejaculates of 3 rams that provide a good quality uniform sperm sample, suitable for representative studies of ram semen avoiding individual differences. A seminal plasma-free sperm population was obtained by a dextran/swim-up procedure as already reported [34] with a medium devoid of $\mathrm{CaCl}_{2}$ and $\mathrm{NaHCO}_{3}$ - (fresh sample).

\section{In vitro capacitation}

For the induction of in vitro capacitation, aliquots of $1.6 \times 10^{8}$ cells/ $\mathrm{ml}$ were incubated for 3 hours at $39^{\circ} \mathrm{C}$ in a humidified incubator with $5 \% \mathrm{CO}_{2}$ in air. Incubations were performed in complete TALP medium [35] containing $100 \mathrm{mM} \mathrm{NaCl}, 3.1 \mathrm{~m}$ DRMs (detergent-resistant membranes) $\mathrm{M} \mathrm{KCl}, 25 \mathrm{mM} \mathrm{NaHCO}_{3}^{-}, 0.3 \mathrm{mM} \mathrm{NaH} \mathrm{PO}_{4}, 21.6 \mathrm{mM}$ $\mathrm{Na}$ lactate, $3 \mathrm{mM} \mathrm{CaCl}, 0.4 \mathrm{mM} \mathrm{MgCl}, 10 \mathrm{mM}$ HEPES, $1 \mathrm{mM} \mathrm{Na}$ pyruvate, $5 \mathrm{mM}$ glucose, and $5 \mathrm{mg} / \mathrm{ml}$ bovine serum albumin, $\mathrm{pH}$ 7.2. Sperm aliquots incubated in this medium were defined as control samples.

To induce capacitation, a previously tested cocktail for capacitating ram spermatozoa [14,15] was added to the sperm aliquots, and defined as capacitated samples. The cocktail consisted of caffeine and theophylline (both inhibitors of phosphodiesterases, Sigma Chemical Co., Madrid, Spain; $1 \mathrm{mM}$ each), okadaic acid (OA, a broad spectrum phosphatase inhibitor, Sigma Chemical Co., Madrid, Spain; $0.2 \mu \mathrm{M}$ ), methyl- $\beta$-cyclodextrin (M- $\beta$-CD, Sigma Chemical Co., Madrid, Spain; $2.5 \mathrm{mM})$ and $1 \mathrm{mM}$ of the cAMP-elevating agent dibutyryl-cAMP ( $\mathrm{db}$ cAMP, Sigma Chemical Co., Madrid, Spain).

\section{Acrosome reaction induction}

The acrosome reaction was induced by the addition of calcium ionophore A23187 (3.4 $\mu \mathrm{M}$ containing 0.3\% DMSO; Sigma Chemical Co., Madrid, Spain) to the swim-up obtained sample $\left(1.6 \times 10^{8}\right.$ sperm/ $\mathrm{ml}$ ) and further incubation at $39^{\circ} \mathrm{C}$ for $1 \mathrm{~h} \mathrm{[36].} \mathrm{Control} \mathrm{tubes} \mathrm{had}$ DMSO added $(0.3 \%)$ but no ionophore, which has been shown to have no effect [36].

\section{Evaluation of sperm samples}

The sperm concentration was calculated in duplicate using a Neubauer's chamber (Marienfeld, Germany).

The capacitation status was assessed by the Chlortetracycline- 
fluorescence (CTC) assay that we had previously validated for the evaluation of capacitation and acrosome reaction-like changes in ram spermatozoa [15]. Three sperm types were estimated [37]: noncapacitated (NC, even distribution of fluorescence on the head, with or without a bright equatorial band), capacitated (C, with fluorescence in the anterior portion of the head) and acrosome-reacted cells (AR, showing no fluorescence on the head). We examined the samples, within $12 \mathrm{~h}$, using a Nikon Eclipse E-400 microscope under epifluorescence illumination with a V-2A filter. All samples were processed in duplicate and we scored at least 150 spermatozoa/slide. No fluorescence was observed when CTC was omitted from the preparation.

\section{Detection of lipid raft markers on ram spermatozoa}

To analyse the presence of caveolin-1, flotillin-1 and flotillin-2, sperm samples were exposed to immunocytochemical staining by an avidin-biotin-peroxidase technique (Vector, CA, USA).Fresh, control and capacitated samples were cytospun onto slides. The cells were fixed in methanol for $15 \mathrm{~min}$ and permeabilized in $3.7 \%$ Triton $\mathrm{X}-100$. After rehydration in PBS pH 7.2, endogenous peroxidase was inactivated with $1.7 \%$ hydrogen peroxide in $100 \%$ ethanol for 30 min. Subsequently, the samples were washed in PBS pH 7.2, and then incubated with a blocking reagent provided with the kit for $45 \mathrm{~min}$, followed by incubation for $2 \mathrm{~h}$ with the primary antibodies: mouse anti-caveolin-1 (1/40), mouse anti-flotillin-1 (1/60), and mouse antiflotillin-2 (1/60) (BD Biosciences, Madrid, Spain). After washing, the slides were incubated with biotinylated anti-mouse antiserum for 40 min. Theavidin-biotin-peroxidase complex was then applied for 45 min. The binding sites of the primary antibodies were visualized by Diaminobenzidine (DAB) and hydrogen peroxide solution $(20 \mathrm{mg}$ $\mathrm{DAB}$ in $100 \mathrm{ml}$ of $0.05 \mathrm{M}$ Tris- $\mathrm{HCl}$ buffer $\mathrm{pH} 7.6$, containing $0.005 \%$ $\mathrm{H}_{2} \mathrm{O}_{2}$ ) for $5 \mathrm{~min}$. After the each incubation, the slides were rinsed with PBS. The samples were visualized under a Nikon Eclipse E400 microscope (Nikon, Tokyo, Japan). Positive staining, indicated by dark brown deposits in some cells, was evaluated according to the obtained sperm pattern and the percentage was estimated. As a positive control, we used an endothelial sample, and as negative controls the primary antibodies were omitted, with the remaining procedure being the same. These negative controls did not show any positive staining.

The distribution of the GM-1 ganglioside on the sperm plasma membrane of the fresh, control and capacitated samples was studied by staining with the Cholera Toxin Subunit B (CTXB)-Alexa488 conjugate (Molecular Probes Inc., Eugene, OR, USA). CTXB binds to GM1 with a high affinity and has been widely used as a reporter of the distribution of lipid rafts [38-40]. Sperm aliquots of $8 \times 10^{6}$ cells were allowed to settle on Poly-L-lysine-coated slides (Sigma Chemical Co., Madrid, Spain). The spermatozoa were firstly incubated for 30 min with $10 \mu \mathrm{g} / \mathrm{ml}$ CTxB-Alexa 488 conjugated at room temperature (RT) in the dark. Secondly, fixation was performed for 10 minutes with $3.7 \%$ formaldehyde at RT. After the each incubation, the slides were rinsed with PBS. Finally, the spermatozoa were mixed with $5 \mu \mathrm{l}$ $0.22 \mathrm{M}$ triethylenediamine (DABCO, Sigma Chemical Co., Madrid, Spain) in glycerol:PBS (9:1) in order to enhance and preserve the cell fluorescence. Finally, the preparations were covered with coverslips, sealed with colourless enamel, and visualized by means of a Nikon Eclipse E400 microscope (Nikon, Tokyo, Japan) under epifluorescence illumination using a B-2A filter. At least 200 cells per sample were evaluated and the percentage of cells displaying positive fluorescence was scored. Negative controls were performed by omitting CTXBAlexa488 and did not reveal positive cells.

\section{Lipid raft isolation}

We used the method described by Hinzpeter et al. [41] with minor modifications. Sperm samples were lysed in cold extraction buffer (TEN buffer (25 mM Tris-HCl pH 7.3, $150 \mathrm{mM} \mathrm{NaCl}, 1 \mathrm{mM}$ EDTA, protease inhibitor cocktail [Sigma Chemical Co, Madrid, Spain], plus 1\% Triton X-100 [Sigma Chemical Co., Madrid, Spain]) for $30 \mathrm{~min}$ and cavitated at 15,000 PSI for $15 \mathrm{~min}$. The lysate was mixed with Optiprep ${ }^{\mathrm{TM}}$ (AxisShield, Dundee, Scotland, UK) to make $1.2 \mathrm{ml}$ of $40 \%$ Optiprep $^{\mathrm{TM}}$ solution and placed at the bottom of an ultracentrifuge tube. The mixture was overlaid with $2.4 \mathrm{ml}$ of $30 \%$ OptiprepTM in TEN buffer followed by an additional $1.2 \mathrm{ml}$ of TEN buffer without Optiprep ${ }^{\mathrm{TM}}$. The samples were spun at $4^{\circ} \mathrm{C}$ overnight $(20 \mathrm{~h})$ or $2 \mathrm{~h}$ at $200,000 \times \mathrm{g}$ in a TLA-110 rotor (Optima TLX Ultracentrifuge). A total of 13 fractions of $400 \mu \mathrm{l}$ were collected and numbered starting at the top of the gradient.

\section{Analysis of the Gradient Fractions}

\section{Quantification of cholesterol}

Cholesterol was measured with the Amplex ${ }^{\oplus}$ Red Cholesterol Assay Kit (Molecular Probes Inc., Eugene, OR, USA), which provides a simple fluorometric method for the sensitive quantitation of cholesterol. Briefly, cholesterol esters are broken down by cholesterol esterase, and then all the cholesterol in the sample is oxidized by cholesterol oxidase to yield $\mathrm{H}_{2} \mathrm{O}_{2}$ and the corresponding ketone product. The $\mathrm{H}_{2} \mathrm{O}_{2}$ is then detected using 10-acetyl-3,7-dihydroxyphenoxazine (Amplex Red reagent, AR), a highly sensitive and stable probe for $\mathrm{H}_{2} \mathrm{O}_{2}$ [42]. In the presence of horseradish peroxidase (HRP), Amplex Red reagent reacts with $\mathrm{H}_{2} \mathrm{O}_{2}$ to produce highly fluorescent resorufin $[42,43]$, which has maxima absorption and fluorescence emission at approximately 571 $\mathrm{nm}$ and $585 \mathrm{~nm}$, respectively. To measure cholesterol in the gradient fractions, $25 \mu \mathrm{l}$ of each fraction were made up to $50 \mu \mathrm{l}$ with PBS, and then mixed with $50 \mu \mathrm{l}$ of a reaction mixture containing $2.087 \mathrm{U} / \mathrm{ml}$ of cholesterol oxidase, $2.087 \mathrm{U} / \mathrm{ml}$ of cholesterol esterase, $2.087 \mathrm{U} /$ $\mathrm{ml}$ of HRP, and $0.312 \mathrm{mM}$ ArR. The reaction was performed for 30 min at $37^{\circ} \mathrm{C}$, protected from the light. The fluorescence was measured at $550 \mathrm{~nm}$ and $590 \mathrm{~nm}$ for absorption and emission, respectively. The concentration of cholesterol was calculated by extrapolating the fluorescence data in a cholesterol standard curve ranging from 0 to 10 $\mu \mathrm{M}$.

\section{Ganglioside GM1 measurement}

Ganglioside GM1 was detected in gradientfractions by dot blot using the cholera toxin subunit B (CTXB) as already reported [44]. Briefly, $5 \mu$ of each fraction were spotted onto previously activated Immobilon-P membranes (Millipore, Bedford, MA, USA). After drying the samples, the membranes were blocked with 5\% skimmed milk for $1 \mathrm{~h}$, at RT. Cholera toxin subunit B-Horseradish Peroxidase conjugate (CTXB-HRP, Sigma Chemical Co., Madrid, Spain), commonly used as a marker for membrane fractions in sub cellular fractionation [45], was added to the membranes at 1/1000 dilution, and incubation was carried out for 1 hour at RT. Extensive washes were made after the incubations. GM1 that bound the CTXB was visualised using the Gel Doc System with Molecular Analyst software (Bio Rad, Hercules, CA) and processed for analysis with PD-QuestTM 2D analysis software (Bio Rad, Hercules, CA) to determine the relative GM1 content of the spots. Negative controls omitting CTXB-HRP showed no reactivity.

\section{Total protein measurement}

The total protein content in gradient fractions was measured using 
the Micro BCA Protein Assay Reagent kit (Pierce, Rockford, IL), according to the manufacturer's indications.

\section{Fatty acid analysis}

Lipids were extracted from gradient fractions by the addition of 6 volumes of chloroform-methanol $(2: 1, \mathrm{v} / \mathrm{v})$, centrifugation at $800 \mathrm{xg}$ for $3 \mathrm{~min}$, and aspiration of the resulting lower phase. Heptadecanoic acid was added to all the samples as an internal standard $(15 \mathrm{mg}$ from chloroform-methanol (1:1, v/v) stock solutions) (Sigma Chemical Co., Madrid, Spain) prior to the extraction. Lower phases were evaporated to dryness under nitrogen. Fatty acids were transmethylated by alkaline methanolysis using the BF3 reagent kit (Supelco, Bellefonte, PA). Dry fractions were resuspended in $0.5 \mathrm{ml}$ of methanolic-base and incubated at $100^{\circ} \mathrm{C}$ for $3 \mathrm{~min}$, followed by the addition of boron trifluoride-methanol $(0.5 \mathrm{ml})$, incubation at $100^{\circ} \mathrm{C}$ for $1 \mathrm{~min}$, addition of hexane $(0.5 \mathrm{ml})$, incubation at $100^{\circ} \mathrm{C}$ for $1 \mathrm{~min}$, and addition of 6.5 $\mathrm{ml}$ of saturated $\mathrm{NaCl}$. The samples were centrifuged at $800 \mathrm{xg}$ for 4 min. The hexane upper layer was transferred to a new glass tube and an aliquot injected in a Hewlett Packard 5890A gas chromatograph. A Supelcowax column of $30 \mathrm{~m}$ length and $0.5 \mathrm{~mm}$ internal diameter was used. The initial temperature was $150^{\circ} \mathrm{C}$ and the final temperature $260^{\circ} \mathrm{C}$. The FID temperature was $300^{\circ} \mathrm{C}$ and the total running time 27 min. Fatty acid methyl ester peaks were identified by comparison with retention times of standard mixtures (Sigma Chemical Co., Madrid, Spain), and quantified in comparison with the internal standard detector response.

\section{Statistical Analysis}

Results are shown as mean \pm SEM of the number of samples indicated in each case. Statistical analyses were carried out using GraphPadInStat software (3.01; San Diego, CA, USA) and SPSS software (v.15.0, IBM, New York, NY, USA). A KolmogorovSmirnov test was performed to establish whether the values came from a Gaussian distribution and thent-test was applied when two groups were compared. Because the lipid/protein ratio data were not normally distributed, and had a lognormal distribution, logarithm transformation of these data was carried out and the Bonferroni test was used. ANOVA tests were performed to determine whether there were significant differences among groups. Raft marker determination data, expressed in percentages, were analysed by means of the chisquare test.

\section{Results}

\section{Raft markers in ram spermatozoa}

In order to identify raft markers in ram spermatozoa, we investigated the presence of caveolin-1, GM1 ganglioside and flotillin-1 and 2 .

Caveolin-1 was located by immunocytochemistry at the acrosomal region of fresh sperm samples, with two different distribution patterns: at the most apical part of the acrosome (type A, Figure 1A), and a more extensive staining on the whole acrosome [type B, Figure 1B]. The quantitative analysis of both patterns revealed $38.5 \pm 3.6 \%$ of type A, $20.6 \pm 6.3 \%$ of type $\mathrm{B}$, and a high percentage of non-stained cells, $40.8 \pm 4.3 \%$ (mean values $\pm S E M ; n=4$ ). Positive (Figure $1 \mathrm{C}$ ) and negative (Figure 1D) controls confirmed the specificity of results. After capacitation, the proportion of type B stained sperm increased (37.7 \pm $4.3 \%, \mathrm{P}<0.05)$ with a concomitant decrease in the percentage of nonstained cells $(27.2 \pm 1.1 \%, \mathrm{P}<0.01)$.
Ganglioside GM1 was evidenced by fluorescence staining in all spermatozoa of fresh samples. The reactivity signal of GM1was located at the post acrosomal region and tail (Figure 2), and only very occasionally at the most apical ridge of the acrosome. Although the intensity of staining was not identical in all spermatozoa, we were not able to discern reliable different staining patterns. Furthermore, we did not find any significant change after capacitation.

Flotillin-1 and flotillin-2 were not detected in ram spermatozoa by either of immunocytochemistry, fluorescence or western-blot analysis.

\section{Isolation of DRMs}

To isolate DRMs from ram spermatozoa, we assayed different times of ultracentrifugation using sperm lysates obtained by incubating fresh samples with Triton X-100. A total of 13 fractions were isolated from the OptiprepTM gradient after ultra centrifuging for either 2 or 20 h. Analyses of cholesterol, ganglioside GM1 and the total protein content were carried out in all fractions. The results obtained (Figure 3) revealed that the lowest-density fractions (1-3) were not enriched in cholesterol and GM1, and that DRMs reached their isopycnic point at the interface between $0-30 \%$ Optiprep $^{\mathrm{TM}}$ that correspond to the

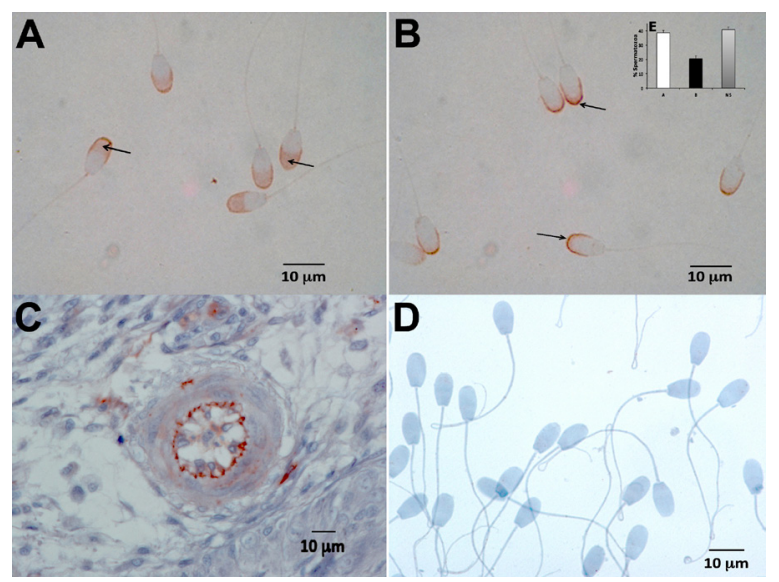

Figure 1: Immunocytochemical localization of caveolin-1 in ram spermatozoa. Two patterns were identified: A) A restricted location in the most apical acrosome (type A); B) An extensive distribution in the acrosome and equatorial regions (type B); Magnification X1000; C) Endothelial cells, positive control. Magnification X600; D) Negative control without the primary antibody. Magnification X1000.E) Quantitative analysis of the stained sperm patterns: at the most apical part of the acrosome (type A), a more extensive staining on the whole acrosome (type B), and non-stained cells (N S) (mean values \pm SEM; $n=4$ ).

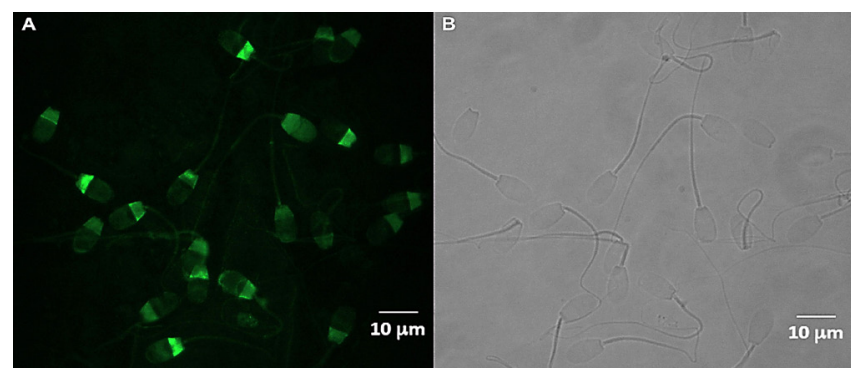

Figure 2: Identification of the ganglioside $\mathrm{GM} 1$ by the Cholera toxin subunit B (CTXB)-Alexa488 conjugate. A) Fluorescence field; B) the respective bright field. Magnification X1000. 


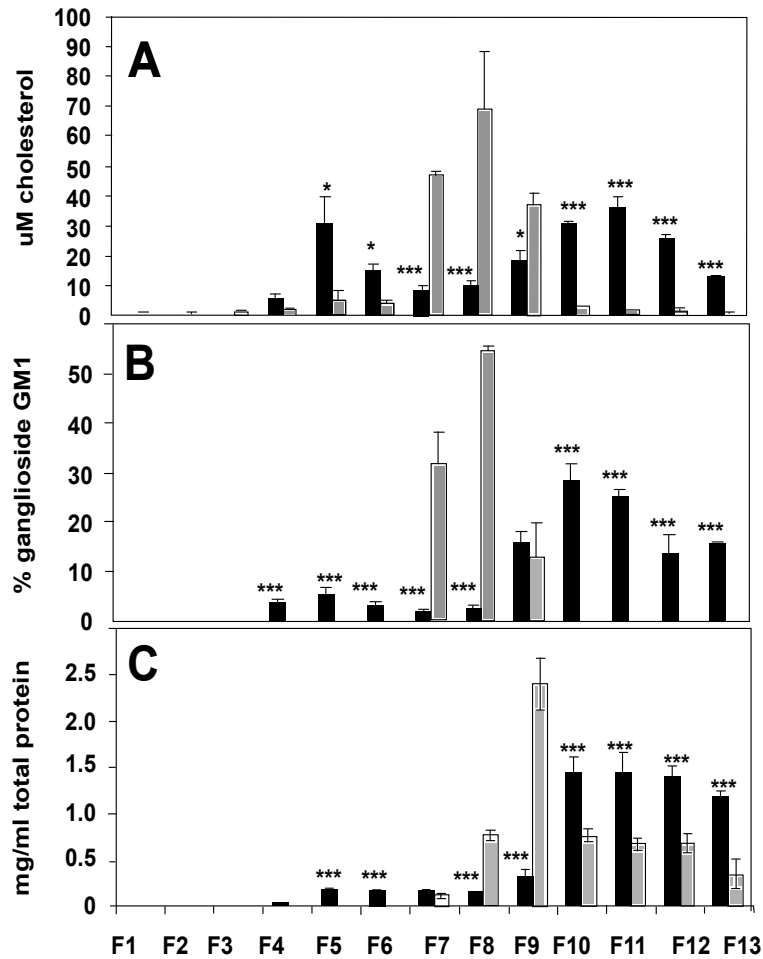

Figure 3: Distribution of (A) cholesterol, $(B)$ ganglioside $G M 1$, and $(C)$ total proteins in the fractions obtained by $2(\mathbf{m})$ or $20 \mathrm{~h}(\mathbf{m})$ ultracentrifugation of Triton X-100 lysates in an OptiprepTM gradient. Mean values \pm SEM $(n=4)$. Significant differences in the same fractions at different ultracentrifugation times: ${ }^{*} P<0.05 ;{ }^{* *} P<0.001$.

fractions 4-5 (DRM fractions). The 30-40\% interface corresponded to fractions 9-10, and non-DRMs (Triton X-100 soluble fractions) were located at the bottom of the gradient.

The comparison of both methods (Figure 3 ) indicated that $2 \mathrm{~h}$ of ultracentrifugation enables a better discrimination between low- and high- density fractions, while after $20 \mathrm{~h}$, cholesterol (Figure 3A) and GM1 (Figure 3B) were concentrated in the medium density fractions (mainly fractions 7,8 , and 9).Based on these results, and given that quantitative protein determination showed that proteins were concentrated in the high-density fractions (10-13, non-DRMs fractions, Figure 3C)with both centrifugation times, $2 \mathrm{~h}$ was established as the ultracentrifugation time for the following experiments.

\section{Changes in DRMs composition after treatments}

The analysis of cholesterol in the fractions separated after $2 \mathrm{~h}$ of ultracentrifugation from lysates of fresh, control, capacitated and acrosome-reacted sperm revealed substantial differences (Figure $4 \mathrm{~A})$. The cholesterol content in fraction 5 (DRMs) of the fresh sperm samples $(25.2 \pm 8.5 \mu \mathrm{M})$ was decreased $(\mathrm{P}<0.01)$ to $4.8 \pm 1.1,3.5 \pm 1.5$ and3.9 $\pm 0.8 \mu \mathrm{M}$ in the control, capacitated and acrosome-reacted samples, respectively. In the non-DRM fractions, a significant loss of cholesterol was also observed in the treated samples compared to the fresh ones $(\mathrm{P}<0.001)$ (Figure $4 \mathrm{~A})$.

Despite the fact that CTC staining was able to significantly discriminate different capacitation patterns (Table 1), the cholesterol content in the gradient-separated fractions was not significantly

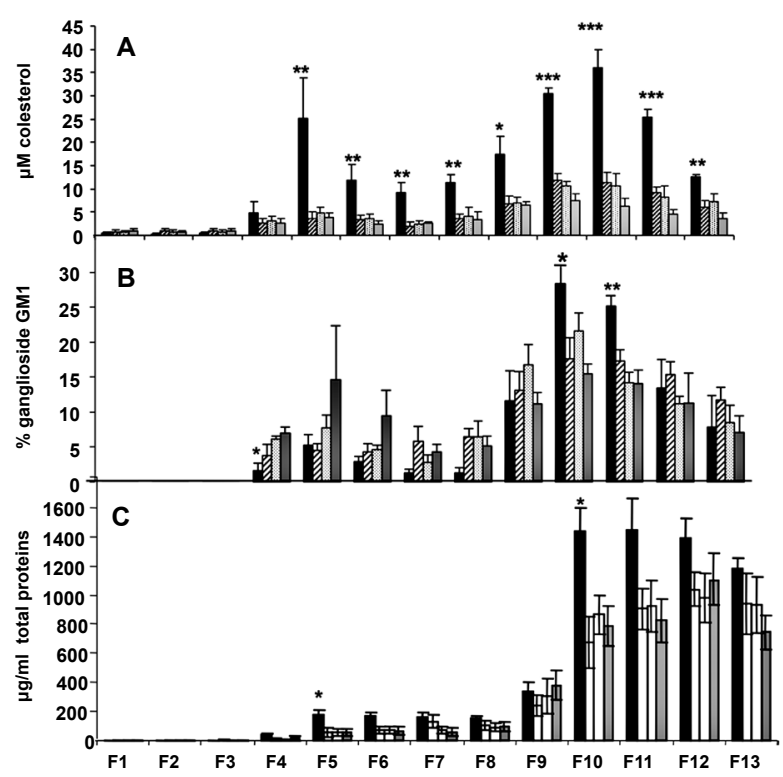

Figure 4: Distribution of (A) cholesterol, (B) ganglioside GM1, and (C) total proteins in the fractions obtained by $2 \mathrm{~h}$ ultracentrifugation of Triton $\mathrm{X}-100$ lysates in

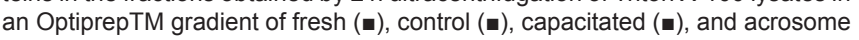
reacted $(\boldsymbol{\square})$ samples. Media \pm SEM $(n=5)$. Significant differences between fresh and control, capacitated or acrosome reacted sperm samples in the same fraction: ${ }^{*} \mathrm{P}<0.05 ;{ }^{* *} \mathrm{P}<0.01$; ${ }^{* * *} \mathrm{P}<0.001$

\begin{tabular}{|l|c|c|c|}
\hline & NC & CAP & AR \\
\hline Fresh & $57.3 \pm 4.9^{\mathrm{a}}$ & $32.3 \pm 1.7^{\mathrm{a}}$ & $10.4 \pm 3.6^{\mathrm{a}}$ \\
\hline Control & $32.4 \pm 10.3^{\mathrm{a}, \mathrm{b}}$ & $43.6 \pm 8.1^{\mathrm{a}, \mathrm{b}, \mathrm{c}}$ & $21.7 \pm 4.2^{\mathrm{a}, \mathrm{b}}$ \\
\hline Capacitated & $7.0 \pm 1.5^{\mathrm{b}, \mathrm{c}}$ & $63.0 \pm 3.8^{\mathrm{b}}$ & $30.0 \pm 3.6^{\mathrm{b}}$ \\
\hline lonophore & $0.5 \pm 0.2^{\mathrm{c}}$ & $28.9 \pm 0.5^{\mathrm{a}, \mathrm{c}}$ & $70.6 \pm 0.8^{\mathrm{c}}$ \\
\hline
\end{tabular}

Values $(\%)$ are presented as mean $\pm \operatorname{SEM}(n=4)$. Different letters in columns indicate significant differences $(P<0.05)$.

NC: non-capacitated; CAP: capacitated; AR: acrosome reacted; CTC: chlortetracycline

Table 1: Percentage of the different sperm subpopulations, according to the CTC staining patterns, in fresh, control, capacitated and acrosome-reacted (AR) samples.

different between the control, capacitated and acrosome-reacted samples (Figure 4A).

GM1 distribution was different from that of cholesterol (Figure $4 \mathrm{~B})$. It is noteworthy that, unexpectedly, it was more abundant in the non-DRM fractions, independently of the physiological state of the sperm. The induction of capacitation and the acrosome reaction resulted in a change in GM1 distribution, which decreased in the nonDRM fractions, especially in fractions 10 and 11, with a concomitant enrichment in DRMs (Figure 4B). Specifically, the GM1 content in fraction 11(non-DRMs) of fresh samples $(25.1 \pm 1.5 \%)$ decreased to $16.4 \pm 1.5,15.4 \pm 0.8$, and $15.9 \pm 0.6 \%$ in the control, capacitated and acrosome-reacted samples, respectively $(\mathrm{P}<0.01)$. Concomitantly, a significant increase in fraction 4 (DRMs) from $3.2 \pm 0.9 \%$ in fresh samples to $6.3 \pm 0.6,6.0 \pm 0.5$, and $7.7 \pm 0.4 \%$ was found in the control, capacitated and acrosome-reacted $(\mathrm{P}<0.05)$ samples, respectively (Figure 4B).

Total protein concentration was measured in all fractions (Figure $4 \mathrm{C})$. The results revealed a very low protein content in the DRM 
fractions. Similarly to that found with cholesterol, the incubation in capacitating conditions (control sample), induced capacitation and acrosome reaction led to a loss of proteins from all the fractions, although significant differences were only found in the fractions 5 (DRMs) and 10 (non-DRMs) $(\mathrm{P}<0.05)$.

As observed in the cholesterol analysis, no significant differences were found between the control, capacitated and acrosome-reacted samples in eitherGM1 or protein content in any fraction.

\section{Fatty acid analysis and saturation index}

The results of fatty acid analysis are summarized in (Table 2). As a general observation, DRM fractions contain a significantly higher level of saturated fatty acids than the heavier fractions $(\mathrm{P}<0.05)$. In addition, the induction of capacitation accounted for a decrease in saturated fatty acid content in both DRM and non-DRM $(\mathrm{P}<0.01)$ fractions (Table 2$)$.

Regarding the percentage of polyunsaturated fatty acids (PUFA), a significantly higher content $(\mathrm{P}<0.05)$ was present in non-DRM fractions, in both fresh and capacitated samples, while no difference was found in the acrosome-reacted samples (Table 2).

The unsaturation index corroborated the results obtained by the fatty acid analysisas it was higher in the non-DRMthan in the DRMfractions in the fresh $(181.4 \pm 17.9$ vs $127.8 \pm 21.2)$, capacitated $(166.3 \pm 8.0$ vs $136.6 \pm 23.2)$ and acrosome-reacted $(209.7 \pm 12.8$ vs $178.2 \pm 55.0)$ samples.

The total fatty acid/protein ratio was significantly higher $(\mathrm{P}<0.001)$ in DRM fractions in fresh, capacitated and acrosome-reacted samples with respect to non-DRM fractions (Table 3). Furthermore, this ratio was significantly increased $(\mathrm{P}<0.001)$ in the capacitation-induced samples in both DRM and non-DRM fractions as compared to fresh and acrosome-reacted samples (Table 3).

\section{Discussion}

In this study, we report for the first time the presence of two lipid raft markers, caveolin-1 and GM1, in ram spermatozoa. Caveolin-1 is a cholesterol-binding protein [46], and a key raft organizer [2547] that has been identified in the acrosomal region of the mouse $[48,49]$, guinea pig [49], stallion [50] and boar [30] spermatozoa. We have identified, by immunocytochemical analysis, caveolin-1 in fresh ram spermatozoa freed from seminal plasma by swim-up. This result indicates the presence of raft-like microdomains in the ram sperm membrane. Caveolin-1 was located at the acrosomal region, although not all sperm were stained. These results corroborate our previous observations about the heterogeneity of the sperm sample obtained by swim-up [51,52], and it is also consistent with those reported for stallion semen in which a relationship between a lack of positive caveolin-1 staining and a reduction in fertility was found [50]. Our results also showed an increase in the proportion of stained sperm at the acrosome, occasionally including the equatorial region, after capacitation. This observation is consistent with previous results showing that the spatial distribution of lipid rafts within the sperm membrane is influenced by the capacitation status [31-53].

Although the presence of flotillin-1 [30] and flotillin -2 [53] has been reported in boar, flotillin-2 in human [54] and, without specifying the type, in ram [55] spermatozoa, our numerous attempts (immunocytochemical, indirect immunofluorescence and westernblot analysis) to identify both flotillins (-1 and -2) failed. However, we succeeded in identifying another raft marker of lipid nature, the ganglioside GM1. GM1 has been reported as a mouse sperm receptor for the seminal plasma protein SVS2 (semen-coagulating protein) that acts as a decapacitating factor [56], which makes GM1 an attractive target for studying sperm physiological changes. Nevertheless, the reported results about the location of GM1 in sperm are contradictory. GM1 has been found at the postacrosome of epididymal mouse [57] and rat [58] spermatozoa, and at the acrosomal area of epididymal murine sperm [59]. Conversely, GM1 was reported as nonexistent or patchy and inconsistent throughout the whole sperm cell of human and boar [31-54]. One likely difference among these studies could be the fixation procedure [60], which might affect viability. In fact, it has been reported that GM1 moves rapidly from its position overlying the acrosome to the post-acrosomal area after cell death in unfixed or lightly fixed samples [59]. Our results show that GM1 is located at the postacrosomal region and tail of all ram spermatozoa. Furthermore, we were unable to observe changes in GM1 location associated with capacitation, although a trend toward the reorganization of GM1 has been suggested in methyl-beta-cyclodextrin-induced capacitated boar sperm [31].

To approach the isolation of DRMs, we considered two main features: their resistance to solubilization with detergents due to the presence of phospholipids containing saturated fatty acyl chains, which confers on them a highly ordered environment [22]; and their low density, a consequence of a relatively higher lipid/protein ratio than bulk membranes. The typical isolation method involves the extraction of cells with $1 \%$ Triton X-100 followed by centrifugation in a discontinuous $5-30 \%$ density gradient [22]. In our conditions, cholesterol and GM1 were distributed all along the gradient, and according to our own interest, a peak of both was found in fraction 5 , just in the upper region of $30 \%$ Optiprep $^{\mathrm{TM}}$ and very near to the $0-30 \%$ Optiprep ${ }^{\mathrm{TM}}$ interface. The proportion of saturated fatty acids

\begin{tabular}{|c|c|c|c|c|c|c|c|c|c|}
\hline \multirow[b]{2}{*}{ Fraction } & \multicolumn{3}{|c|}{$\%$ saturated fatty acids } & \multicolumn{3}{|c|}{$\%$ PUFA } & \multicolumn{3}{|c|}{ Unsaturation Index } \\
\hline & Fresh & CAP & AR & Fresh & CAP & AR & Fresh & CAP & AR \\
\hline F4 & $55.9 \pm 6.9^{a}$ & $40.4 \pm 2.7^{b}$ & $55.8 \pm 9.1^{b}$ & $22.3 \pm 3.5$ & $20.3 \pm 10.7$ & $15.8 \pm 5.4$ & $133.6 \pm 19.1$ & $130.0 \pm 52.8$ & $123.6 \pm 18.6$ \\
\hline F5 & $57.4 \pm 8.4^{\mathrm{a}}$ & $41.1 \pm 7.6^{\mathrm{b}}$ & $49.2 \pm 18.4^{\mathrm{a}, \mathrm{b}}$ & $18.0 \pm 8.5^{\mathrm{a}}$ & $18.2 \pm 2.3^{\mathrm{a}}$ & $39.8 \pm 15.5^{b}$ & $121.9 \pm 43.0$ & $143.1 \pm 5.7$ & $232.8 \pm 108.9$ \\
\hline DRMs & $56.6 \pm 4.8^{a, 1}$ & $40.8 \pm 3.6^{b}$ & $52.5 \pm 8.6^{a, 1}$ & $20.1 \pm 4.2^{\mathrm{a}, 1}$ & $19.2 \pm 4.9^{\mathrm{a}, 1}$ & $27.8 \pm 9.6^{b}$ & $127.8 \pm 21.2$ & $136.6 \pm 23.9$ & $178.2 \pm 55.0$ \\
\hline F10 & $42.8 \pm 6.8^{\mathrm{a}}$ & $35.6 \pm 4.3^{\mathrm{a}}$ & $52.0 \pm 2.0^{\mathrm{b}}$ & $33.4 \pm 3.8$ & $29.5 \pm 6.2$ & $30.3 \pm 3.7$ & $211.6 \pm 23.8$ & $185.6 \pm 17.7$ & $208.4 \pm 40.7$ \\
\hline F11 & $47.5 \pm 7.4$ & $40.1 \pm 3.9$ & $46.9 \pm 1.7$ & $24.8 \pm 10.3$ & $28.0 \pm 7.0$ & $27.6 \pm 8.2$ & $165.8 \pm 53.9$ & $158.7 \pm 21.9$ & $226.1 \pm 8.0$ \\
\hline F12 & $45.6 \pm 5.8$ & $42.6 \pm 5.1$ & $46.0 \pm 11.5$ & $24.6 \pm 9.5$ & $24.2 \pm 7.6$ & $26.2 \pm 0.6$ & $165.7 \pm 47.7$ & $150.8 \pm 14.7$ & $200.9 \pm 36.2$ \\
\hline F13 & $45.3 \pm 5.8^{a}$ & $36.3 \pm 2.6^{b}$ & $40.0 \pm 7.9^{a, b}$ & $27.7 \pm 3.4^{\mathrm{a}}$ & $35.8 \pm 3.3^{b}$ & $23.6 \pm 3.9^{\mathrm{a}}$ & $182.2 \pm 26.0$ & $169.7 \pm 8.9$ & $203.4 \pm 34.4$ \\
\hline Non-DRMs & $45.3 \pm 2.8^{a, 2}$ & $38.7 \pm 1.9^{b}$ & $46.2 \pm 3.1^{\mathrm{a}, 2}$ & $27.6 \pm 3.3^{2}$ & $29.3 \pm 2.9^{2}$ & $26.9 \pm 2.0$ & $181.4 \pm 17.9$ & $166.3 \pm 8.0$ & $209.7 \pm 12.8$ \\
\hline
\end{tabular}

Different superscript letters between columns indicate significant differences $(P<0.01)$

Different superscript numbers between rows indicate significant differences $(P<0.05)$.

CAP: capacitated; AR: acrosome reacted.

Table 2: Analysis of fatty acids by gas chromatography infractions obtained from the Optiprep gradients $(n=3)$ 


\begin{tabular}{|l|l|l|l|}
\hline \multicolumn{1}{|c|}{ Fractions } & \multicolumn{1}{c|}{ Fresh } & \multicolumn{1}{c|}{ CAP } & \multicolumn{1}{c|}{ AR } \\
\hline DRMs & $8.4 \pm 0.77^{\mathrm{a}, 1}$ & $661.2 \pm 51.8^{\mathrm{b}, 1}$ & $235.4 \pm 0.8^{\mathrm{b}, 1}$ \\
\hline Non DRMs & $1.3 \pm 0.36^{\mathrm{a}, 2}$ & $42.8 \pm 8.0^{\mathrm{b}, 2}$ & $33.8 \pm 5.8^{\mathrm{b}, 2}$ \\
\hline
\end{tabular}

Different superscript letters between columns indicate significant differences $(\mathrm{P}<$ 0.001).

Different superscript numbers between rows indicate significant differences $(\mathrm{P}<$ 0.001).

CAP: capacitated; AR: acrosome reacted

Table 3: Total lipid/total protein ratio in the fractions obtained from the OptiprepTM gradients $(n=3)$

was higher in the DRM fractions, which was confirmed by the analysis of the unsaturation index. Consequently, the environment in DRMs is more ordered than in non-DRMs, as expected. These results verify that DRMs were isolated in a discrete region of the gradient, mainly fractions 4 and 5, and are consistent with the lipid/protein ratio value that was higher in DRM fractions.

In vitro treatments caused significant changes in the distribution of the mentioned markers in the gradient separated fractions: cholesterol was partially lost from all the fractions (DRMs and non-DRMs), which is consistent with our previous results [14,15], while GM1 decreased in the heaviest fractions with a concomitant enrichment in the lighter ones. This modification can be interpreted as a transition of the ganglioside from non-DRMs to DRMs and indicates that the composition of lipid rafts is modified during incubation in capacitating conditions and the acrosome reaction. The efflux of cholesterol from DRMs and non-DRMs means that the sperm plasma membrane suffers reorganization and topographic changes of certain molecules, which would result in the shift of ganglioside GM1 from non-DRMs to DRMs. However, whether this change of distribution is a result of coalescence of smaller rafts into higher rafts, or is due to the formation of new rafts, needs further investigation.

There is no consensus about the effect of capacitation and the acrosome reaction on lipid rafts. While some authors have suggested that lipid rafts increase during capacitation [30,31-53], a loss of lipid rafts following capacitation has been reported in mouse spermatozoa [48]. An important implication of our results is that the sperm membrane changes induced by capacitation (cAMP elevating agents) accounted for a decrease in the content of saturated fatty acids in both DRM and non-DRM, with a higher effect in DRMs where their content is higher. The calcium ionophore resulted in increased polyunsaturated fatty acids in DRM fractions. These results suggest that both the cAMP and calcium pathways would be implicated in lipid raft remodelling in ram spermatozoa.

Our results showed that cholesterol is very abundant in non-DRM fractions. We could argue that this is a feature specific for certain species such as the ovine, with a very low cholesterol:phospholipid ratio (0.38) [19]. Likewise, the cholesterol content in DRM fractions is lower than that in Triton-soluble fractions of bovine spermatozoa [61]. Similar data have been reported in epithelial cells [62] and suggest that the low cholesterol content in DRM fractions might reflect a physiological state and probably be dependent on the cell type.

The content of cholesterol in the separated fractions was not significantly different between the control, capacitated and acrosomereacted samples, although the CTC staining was able to discriminate different capacitation patterns in agreement with previous reports [63]. An interesting feature about cholesterol is that, while we were not able to evidence its efflux linked to capacitation in ram spermatozoa [14], the results of this study confirmed a loss of cholesterol from DRMs and non-DRMs fractions in capacitated and acrosome-reacted sperm. Therefore, although the removal of cholesterol is not necessary for in vitro ram sperm capacitation $[14,15]$, these data reconcile our results with those of other authors who stated that capacitation is linked to an efflux of cholesterol from the plasma membrane $[64,65]$. This reduction in the content of cholesterol is believed to affect its topology and takes place in certain areas of the plasma membrane[66]. Interestingly, the presence of $\mathrm{m}-\beta-\mathrm{CD}$, a cholesterol-depleting agent, in the capacitation inducing medium did not seem to have an influence in the general decrease in cholesterol content, as no significant differences in cholesterol were found between control, capacitated and acrosomereacted samples.

The protein composition of lipid rafts has been analysed $[22,67,68]$ The identified and raft-associated proteins have been involved in numerous biological processes, including signal transduction events, membrane component sorting, viral budding, toxin entry into the cells, prion action, and amyloid formation [69]. Our results showed that the amount of proteins in DRMs of ram spermatozoa is lower than that reported in boar [30] and mouse [48]. Furthermore, proteins from DRMs and non-DRMs are lost after capacitation and the acrosome reaction. These results are consistent with previous reports that describe the release of sperm membrane proteins during capacitation of bull [70], boar [71,72], rabbit [73] or ram [74] spermatozoa.

We have already shown that RSVP14 and RSVP20 (ram seminal plasma proteins) are adsorbed onto the ejaculated ram sperm surface [75], and that they are redistributed and partially lost from the plasma membrane during in vitro capacitation and the acrosome reaction (only approximately $35 \%$ of them remained on the spermatozoa after both processes, [76]. Thus, we can speculate that there is both a loss and a redistribution of proteins in discrete plasma membrane domains. In fact, some proteins found in the epididymal fluid have been located in lipid rafts of spermatozoa: Prp in ram [55], and AQN-3 (also known as spermadhesin) [77] and P47 (the SED1 porcine homologue) [78] in boar spermatozoa.

It has also been demonstrated that DRMs isolated from spermatozoa possess the ability to bind with high affinity and specificity to the zona pellucidae of homologous oocytes [53-79]. Although caution is required in equating DRM association of a protein with its residence in membrane raft domains in situ [80], such findings encourage the speculation that sperm membrane rafts serve as constitutive platforms for the spatial constraint of key recognition molecules and that the remodeling events associated with capacitation lead to their assembly and presentation on the outer leaflet of the sperm plasma membrane [81]. Likewise, it has been reported that DRMs of ejaculated spermatozoa are reorganized by seminal plasma proteins which are responsible for the dissociation of certain proteins from DRM domains [61]. In this context it is tempting to speculate that RSVP14 and RSVP20 might associate with discrete plasma membrane microdomains, and that seminal plasma might play an important role in the behaviour and composition of lipid rafts.

The study of sperm membrane surface remodelling based on the new concept of membrane lipid microdomains may contribute to a better understanding of the mechanism leading to the acquisition of sperm fertilizing potential. The association of specific proteins involved in gamete interaction with these lipid microdomains represents a promising matter for future research.

\section{Acknowledgements}

Supported by grants CICYT-FEDER AGL 2011-25850 and DGA A-26. The authors thank ANGRA for supplying the sires and S. Morales for the collection of 
Citation: Colas C, Perez-Pe R, Casao A, Ollero M, Calleja L, et al. (2012) Remodelling of Lipid Rafts during In vitro Capacitation and Acrosome Reaction of Ram Spermatozoa. Biochem Anal Biochem S5-001. doi:10.4172/2161-1009.S5-001

semen samples.

\section{References}

1. Amann RP, Hammerstedt RH, Veeramachaneni DN (1993) The epididymis and sperm maturation: a perspective. Reprod Fertil Dev 5: 361-381.

2. Hammerstedt RH, Parks JE (1987) Changes in sperm surfaces associated with epididymal transit. J Reprod Fertil Suppl 34: 133-149.

3. Bruckbauer A, James P, Zhou D, Yoon JW, Excell D, et al. (2007) Nanopipette delivery of individual molecules to cellular compartments for single-molecule fluorescence tracking. Biophys J 93: 3120-3131.

4. Wolfe CA, James PS, Mackie AR, Ladha S, Jones R (1998) Regionalized lipid diffusion in the plasma membrane of mammalian spermatozoa. Biol Reprod 59: $1506-1514$

5. De Leeuw FE, Chen HC, Colenbrander B, Verkleij AJ (1990) Cold-induced ultrastructural changes in bull and boar sperm plasma membranes. Cryobiology 27: 171-183

6. Singer SJ, Nicholson GL (1972) The fluid mosaic model of the structure of cell membranes. Science 175: 720-731.

7. Pike LJ (2006) Rafts defined: a report on the Keystone Symposium on Lipid Rafts and Cell Function. J Lipid Res 47: 1597-1598.

8. London E, Brown DA (2000) Insolubility of lipids in Triton X-100: physical origin and relationship to sphingolipid/cholesterol membrane domains (rafts). Biochim Biophys Acta1508: 182-195.

9. Gadella BM, Tsai PS, Boerke A, Brewis IA (2008) Sperm head membrane reorganisation during capacitation. Int J Dev Biol 52: 473-480.

10. Cross NL (2003) Decrease in order of human sperm lipids during capacitation. Biol Reprod 69: 529-534.

11. Harrison RA, Gadella BM (2005) Bicarbonate-induced membrane processing in sperm capacitation. Theriogenology 63: 342-351.

12. Yanagimachi R (1994) Mammalian Fertilization. In: Knobil E,Neill JD (eds), The Physiology of Reproduction. (2nd edn) Raven Press Ltd, New York.

13. Parks JE, Hammerstedt RH (1985) Developmental changes occurring in the lipids of ram epididymal spermatozoa plasma membrane. Biol Reprod 32: 653668

14. Colás C, James P, Howes L, Jones R, Cebrián-Pérez JA, et al. (2008) CyclicAMP initiates protein tyrosine phosphorylation independent of cholesterol efflux during ram sperm capacitation. Reprod Fertil Dev 20: 649-658.

15. Grasa P, Cebrián-Pérez JA, Muiño-Blanco T (2006) Signal transduction mechanisms involved in in vitro ram sperm capacitation. Reproduction 132: 721-732.

16. Davis BK (1981) Timing of fertilization in mammals: sperm cholesterol/phospholipid ratio as a determinant of the capacitation interval. Proc Natl Acad Sci USA 78: 7560-7564.

17. Ladbrook BD, Chapman D (1969) Thermal Analysis of Lipids, Proteins and Biological Membranes. A Review and Summary of Some Recent Studies. Chem Phys Lipids 3: 304-356.

18. Watson PF (1981) The effects of cold shock on sperm cell membranes. In: Morris GJ, Clarke A (Eds), Effects of low temperatures on biological membranes. Academic Press, London.

19. Darin-Bennett A, White IG (1977) Influence of the cholesterol content of mammalian spermatozoa on susceptibility to cold-shock. Cryobiology 14: 466-470.

20. Poulos A, Voglmayr JK, White IG (1973) Phospholipid changes in spermatozoa during passage through the genital tract of the bull. Biochim Biophys Acta 306 : 194-202.

21. Asano A, Selvaraj V, Buttke DE, Nelson JL, Green KM, et al. (2009) Biochemical characterization of membrane fractions in murine sperm: identification of three distinct sub-types of membrane rafts. J Cell Physiol 218: 537-548.

22. Brown DA, Rose JK (1992) Sorting of GPI-anchored proteins to glycolipid-enriched membrane subdomains during transport to the apical cell surface. Cell 68: 533-544.

23. Quinn PJ (2010) A lipid matrix model of membrane raft structure. Prog Lipid Res 49: 390-406

24. Sargiacomo M, Sudol M, Tang Z, Lisanti MP (1993) Signal transducing mol- ecules and glycosyl-phosphatidylinositol-linked proteins form a caveolin-rich insoluble complex in MDCK cells. J Cell Biol 122: 789-807.

25. Rothberg KG, Heuser JE, Donzell WC, Ying YS, Glenney JR, et al. (1992) Caveolin, a Protein-Component of Caveolae Membrane Coats. Cell 68: 673-682.

26. Mishra S, Joshi PG (2007) Lipid raft heterogeneity: an enigma. J Neurochem 103: $135-142$

27. Inoue T, Sugiyama D, Kurita R, Oikawa T, Kulkeaw K, et al. (2011) APOA-1 is a novel marker of erythroid cell maturation from hematopoietic stem cells in mice and humans. Stem Cell Rev 7: 43-52.

28. van Gestel RA, Brewis IA, Ashton PR, Brouwers JF, Gadella BM (2007) Multiple proteins present in purified porcine sperm apical plasma membranes interac with the zona pellucida of the oocyte. Mol Hum Reprod 13: 445-454.

29. Boerke A, Tsai PS, Garcia-Gil N, Brewis IA, Gadella BM (2008) Capacitationdependent reorganization of microdomains in the apical sperm head plasma membrane: functional relationship with zona binding and the zona-induced acrosome reaction. Theriogenology 70: 1188-1196.

30. van Gestel RA, Brewis IA, Ashton PR, Helms JB, Brouwers JF, et al. (2005) Capacitation-dependent concentration of lipid rafts in the apical ridge head area of porcine sperm cells. Mol Hum Reprod 11: 583-590.

31. Shadan S, James PS, Howes EA, Jones R (2004) Cholesterol efflux alters lipid raft stability and distribution during capacitation of boar spermatozoa. Bio Reprod 71: 253-265.

32. Selvaraj V, Buttke DE, Asano A, McElwee JL, Wolff CA, et al. (2007) GM1 dy namics as a marker for membrane changes associated with the process of capacitation in murine and bovine spermatozoa. J Androl 28: 588-599.

33. Ollero M, Muiño-Blanco T, López-Pérez MJ, Cebrián-Pérez JA (1996) Viability of ram spermatozoa in relation to the abstinence period and successive ejaculations. Int J Androl 19: 287-292.

34. García-López N, Ollero M, Muiño-Blanco T, Cebrián-Pérez JA (1996) A dextran swim-up procedure for separation of highly motile and viable ram spermatozoa from seminal plasma. Theriogenology 46: 141-151.

35. Parrish JJ, Susko-Parrish J, Winer MA, First NL (1988) Capacitation of bovine sperm by heparin. Biol Reprod 38: 1171-1180.

36. Martí JI, Cebrián-Pérez JA, Muiño-Blanco T (2000) Assessment of the acrosomal status of ram spermatozoa by RCA lectin-binding and partition in an aqueous two-phase system. J Androl 21: 541-548.

37. Gillan L, Evans G, Maxwell WM (1997) Capacitation status and fertility of fresh and frozen-thawed ram spermatozoa. Reprod Fert Dev 9: 481-487.

38. Kenworthy AK, Petranova N, Edidin M (2000) High-resolution FRET microscopy of cholera toxin B-subunit and GPI-anchored proteins in cell plasma membranes. Mol Biol Cell 11: 1645-1655.

39. Tuosto L, Parolini I, Schröder S, Sargiacomo M, Lanzavecchia A, et al. (2001) Organization of plasma membrane functional rafts upon $T$ cell activation. Eur $J$ Immunol 31: 345-349.

40. Viola A, Schroeder S, Sakakibara Y, Lanzavecchia A (1999) T Iymphocyte costimulation mediated by reorganization of membrane microdomains. Science 283: 680-682.

41. Hinzpeter A, Fritsch J, Borot F, Trudel S, Vieu DL, et al. (2007) Membrane cholesterol content modulates $\mathrm{CIC}-2$ gating and sensitivity to oxidative stress. J BiolChem 282: 2423-2432.

42. Zhou M, Diwu Z, Panchuk-Voloshina N, Haugland RP (1997) A stable nonfluorescent derivative of resorufin for the fluorometric determination of trace hydrogen peroxide: Applications in detecting the activity of phagocyte NADPH oxidase and other oxidases. Anal Biochem 253: 162-168.

43. Mohanty JG, Jaffe JS, Schulman ES, Raible DG (1997) A highly sensitive fluorescent micro-assay of $\mathrm{H} 2 \mathrm{O} 2$ release from activated human leukocytes using a dihydroxyphenoxazine derivative. J Immunol Meth 202: 133-141.

44. Sepúlveda MR, Berrocal-Carrillo M, Gasset M, Mata AM (2006) The plasma membrane $\mathrm{Ca} 2+-$ ATPase isoform 4 is localized in lipid rafts of cerebellum synaptic plasma membranes. J Biol Chem 281: 447-453.

45. Hawari FI, Rouhani FN, Cui X, Yu ZX, Buckley C, et al. (2004) Release of fulllength 55-kDa TNF receptor 1 in exosome-like vesicles: a mechanism for generation of soluble cytokine receptors. Proc Natl Acad Sci USA 101: 1297-1302. 
Citation: Colas C, Perez-Pe R, Casao A, Ollero M, Calleja L, et al. (2012) Remodelling of Lipid Rafts during In vitro Capacitation and Acrosome Reaction of Ram Spermatozoa. Biochem Anal Biochem S5-001. doi:10.4172/2161-1009.S5-001

46. Murata M, Peränen J, Schreiner R, Wieland F, Kurzchalia TV, et al (1995) Vip21/Caveolin Is a Cholesterol-Binding Protein. Proc Natl Acad Sci USA 92: 10339-10343.

47. Simons K, Ikonen E (1997) Functional rafts in cell membranes. Nature 387 569-572.

48. Sleight SB, Miranda PV, Plaskett NW, Maier B, Lysiak J, et al. (2005) Isolation and proteomic analysis of mouse sperm detergent-resistant membrane fractions: evidence for dissociation of lipid rafts during capacitation. Biol Reprod 73: $721-729$.

49. Travis AJ, Merdiushev T, Vargas LA, Jones BH, Purdon MA, et al. (2001) Expression and localization of caveolin-1, and the presence of membrane rafts, in mouse and Guinea pig spermatozoa. Dev Biol 240: 599-610.

50. Gamboa S, Ramalho-Santos J (2005) SNARE proteins and caveolin-1 in stallion spermatozoa: possible implications for fertility. Theriogenology 64: 275 291.

51. Grasa P, Martí JI, Muiño-Blanco T, Cebrián-Pérez JA (2003) Different functional states of ram spermatozoa analysed by partition in an aqueous two-phase system. J Chromatogr B Analyt Technol Biomed Life Sci 795: 83-91.

52. Grasa P, Pérez-Pé R, Abecia A, Forcada F, Muiño-Blanco T, et al. (2005) Sperm survival and heterogeneity are correlated with fertility after intrauterine insemination in superovulated ewes. Theriogenology 63: 748-762.

53. Bou Khalil M, Chakrabandhu K, Xu H, Weerachatyanukul W, Buhr M, et al (2006) Sperm capacitation induces an increase in lipid rafts having zona pellucida binding ability and containing sulfogalactosylglycerolipid. Dev Biol 290: 220-235.

54. Cross NL (2004) Reorganization of lipid rafts during capacitation of human sperm. Biol Reprod 71: 1367-1373.

55. Ecroyd H, Sarradin P, Dacheux JL, Gatti JL (2004) Compartmentalization of prion isoforms within the reproductive tract of the ram. Biol Reprod 71: 993-1001.

56. Kawano N, Yoshida K, Iwamoto T, Yoshida M (2008) Ganglioside GM1 mediates decapacitation effects of SVS2 on murine spermatozoa. Biol Reprod 79 : 1153-1159.

57. Treviño CL, Serrano CJ, Beltrán C, Felix R, Darszon A (2001) Identification of mouse trp homologs and lipid rafts from spermatogenic cells and sperm. FEBS Lett 509: 119-125.

58. Roberts KP, Wamstad JA, Ensrud KM, Hamilton DW (2003) Inhibition of capacitation-associated tyrosine phosphorylation signaling in rat sperm by epididymal protein crisp-1. Biol Reprod 69: 572-581.

59. Selvaraj V, Asano A, Buttke DE, McElwee JL, Nelson JL, et al. (2006) Segregation of micron-scale membrane sub-domains in live murine sperm. $\mathrm{J}$ Cell Physiol 206: 636-646.

60. Buttke DE, Nelson JL, Schlegel PN, Hunnicutt GR, Travis AJ (2006) Visualization of $\mathrm{G}(\mathrm{M} 1)$ with cholera toxin $B$ in live epididymal versus ejaculated bull, mouse, and human spermatozoa. Biol Reprod 74: 889-895.

61. Girouard J, Frenette G, Sullivan R (2008) Seminal plasma proteins regulate the association of lipids and proteins within detergent-resistant membrane domains of bovine spermatozoa. Biol Reprod 78: 921-931.

62. Legler DF, Doucey MA, Schneider P, Chapatte L, Bender FC, et al. (2004) Differential insertion of GPI-anchored GFPs into lipid rafts of live cells. FASEB J 19: 73-75.

63. Colás C, Muiño-Blanco T, Cebrián-Pérez JA (2010) Caffeine induces ram sperm hyperactivation independent of cAMP-dependent protein kinase. Int J Androl 33: 187-197.

64. Davis BK, Byrne R, Hungund B (1979) Studies on the mechanism of capacitation. II. Evidence for lipid transfer between plasma membrane of rat sperm and serum albumin during capacitation in vitro. Biochim Biophys Acta 558: 257-266.

65. Visconti PE, Stewart-Savage J, Blasco A, Battaglia L, Miranda P, et al. (1999) Roles of bicarbonate, CAMP, and protein tyrosine phosphorylation on capacitation and the spontaneous acrosome reaction of hamster sperm. Biol Reprod 61: $76-84$

This article was originally published in a special issue, Membrane Biochemistry handled by Editor(s). Dr. Katy Schmidt, University Medical Center Utrecht, The Netherlands
66. Leahy T, Gadella BM (2011) Capacitation and Capacitation-like Sperm Surface Changes Induced by Handling Boar Semen. Reprod Domest Anim 46: 7-13.

67. Anderson RG (1998) The caveolae membrane system. Annu Rev Biochem 67 $199-225$

68. Brown DA, London E (1998) Functions of lipid rafts in biological membranes Annu Rev Cell Dev Biol 14: 111-136.

69. Xu X, London E (2000) The effect of sterol structure on membrane lipid do mains reveals how cholesterol can induce lipid domain formation. Biochemistry 39: $843-849$

70. Desnoyers L, Manjunath P (1992) Major proteins of bovine seminal plasma exhibit novel interactions with phospholipid. J Biol Chem 267: 10149-10155.

71. Caballero I, Vazquez JM, Garcia EM, Roca J, Martinez EA, et al. (2006) Immunolocalization and possible functional role of PSP-I/PSP-II heterodimer in highly extended boar spermatozoa. J Androl 27: 766-773.

72. Dostalova Z, Calvete JJ, Sanz L, Topferpetersen E (1994) Quantitation of Boar Spermadhesins in Accessory Sex Gland Fluids and on the Surface of Epididy mal, Ejaculated and Capacitated Spermatozoa. Biochim Biophys Acta1200: 48-54.

73. Oliphant G (1976) Removal of Sperm-Bound Seminal Plasma Components as a Prerequisite to Induction of Rabbit Acrosome Reaction. Fertil Steril 27: 28-38.

74. Barrios B, Perez-Pe R, Gallego M, Tato A, Osada J, et al. (2000) Semina plasma proteins revert the cold-shock damage on ram sperm membrane. Bio Reprod 63: 1531-1537.

75. Fernandez-Juan M, Gallego M, Barrios B, Osada J, Cebriaán-Pérez JA, et al (2006) Immunohistochemical localization of sperm-preserving proteins in the ram reproductive tract. J Androl 27: 588-595.

76. Barrios B, Fernandez-Juan M, Muiño-Blanco T, Cebrián-Pérez JA (2005) Immunocytochemical localization and biochemical characterization of two seminal plasma proteins that protect ram spermatozoa against cold shock. J Andro 26: $539-549$

77. Calvete JJ, Carrera E, Sanz L, Topfer-Petersen E (1996) Boar spermadhesin AQN-1 and AQN-3: oligosaccharide and zona pellucida binding characteristics. Biol Chem 377: 521-527

78. Ensslin MA, Shur BD (2007) The EGF repeat and discoidin domain protein SED1/MFG-E8, is required for mammary gland branching morphogenesis. Proc Natl Acad Sci U S A 104: 2715-2720.

79. Nixon B, Bielanowicz A, McLaughlin EA, Tanphaichitr N, Ensslin MA, et al. (2009) Composition and significance of detergent resistant membranes in mouse spermatozoa. J Cell Physiol 218: 122-134.

80. Munro S (2003) Lipid rafts: elusive or illusive? Cell 115: 377-388.

81. Nixon B, Aitken RJ, McLaughlin EA (2007) New insights into the molecular mechanisms of sperm-egg interaction. Cell Mol Life Sci 64: 1805-1823. 